\title{
Trends in waist to thigh ratio among adults in US
}

\author{
M.F. Faramawi ${ }^{\text {a }}$, S. Gandhi ${ }^{\text {b }}$, J.L. Caffrey ${ }^{\text {b }}$, M. Felini ${ }^{\text {b }}$, S. Bae ${ }^{\text {c }}, \underline{\text { K.P. Singh }}{ }^{\text {c }}$ \\ ${ }^{a}$ University of Arkansas for Medical Sciences, AR, USA \\ ${ }^{b}$ University of North Texas Health Science Center, Fort Worth, TX, USA \\ ${ }^{c}$ University of Alabama at Birmingham, Birmingham, AL, USA \\ Email: karansingh@uabmc.edu
}

\begin{abstract}
The burden of obesity is increasing in the US. Waist to thigh ratio has been proposed as a measure of central obesity. Waist thigh ratio (WTR) has been proposed as an index for abdominal (central) obesity. Epidemiological studies have demonstrated that an increased WTR is a strong predictor for type 2 diabetes and ischemic heart disease. WTR can be used as an inexpensive screening tool to detect unhealthy body shapes and to provide these individuals with the appropriate management to decrease their risk for heart disease and diabetes. Changes in waist to thigh ratio over time in representative samples of US adults were not examined before. Our objective was to examine temporal trends in waist thigh ratio among US adults. Analysis of data collected from 30,001 adults ( $>=20$ years old) who participated in the National Health and Nutrition Examination Survey from 1988 to 1994 and continuous National Health and Nutrition Examination Surveys conducted between 1999 and 2006. The crude and age standardized waist to thigh ratio means increased among males, females and different age groups between 1988 and 2006. Age, gender, race and time were statistically significant predictors for waist thigh ratio ( $\mathrm{P}$ values $<0.01)$. These results document the increase in abdominal obesity among U.S. adults between 1988 and 2006. Efforts should be made to slow the increasing waist thigh ratio among in the US population.
\end{abstract}

Keywords: Epidemiology, Obesity 


\section{INTRODUCTION}

The epidemic of obesity in the U.S. has been well documented (Flegal et al.,2002, Mokdad et al.,2003). Waist thigh ratio (WTR) has been proposed as an index for abdominal (central) obesity (Li et al.,2010). Waist circumference represents variability in intra-abdominal and subcutaneous fat (Reis et al.,2009). Thigh circumference reflects variability in subcutaneous fat, muscle mass, and bone width (Reis et al.,2009). Hence, the combination of waist with thigh circumferences may provide unique prognostic information about these two important body sites. An increased WTR may reflect a relative abundance of visceral fat, decreased peripheral fat or muscle, or both. Thus, WTR does not only reflect variation in visceral fat accumulation, but also provides an estimate of body shape or fat distribution, which is strongly predictive of mortality. (Reis et al.,2009) Epidemiological studies have demonstrated that an increased WTR is a strong predictor for type 2 diabetes (Chuang et al.,2006, Kaur et al.,2008, Weyer et al.,1999) and ischemic heart disease (Kahn et al.,1996). WTR can be used as an inexpensive screening tool to detect unhealthy body shapes (Chuang et al.,2006) and to provide these individuals with the appropriate management to decrease their risk for heart disease and diabetes. WTR data for National Health and Nutrition Examination Survey (NHANES) III and continuous NHANES surveys (1999-2006) have been collected from participants $\geq 20$ years old. Yet, changes in WTR among U.S adults over time were not examined before. Therefore, in this study changes in the WTR among the US adults from 1988 to 2006

\section{METHOD:}

NHANES III (1988 to 1994) and Continuous NHANES (1999 to 2006) cross-sectional surveys of the U.S. population were utilized in this analysis. In these surveys standardized questionnaires were administered in the participants' home by a trained interviewer. Self-reported data relevant to the current analysis included demographics (age, race and gender). After an interview in the home, participants were examined in the mobile examination center (MEC). The waist and thigh measurement data were collected by trained health technicians. The waist and thigh circumferences were measured with a measuring tape. The measure is recorded in centimeters to the nearest millimeter.

\section{NHANES III (1988 TO 1994) AND CONTINUOUS NHANES (1999 TO 2006)}

NHANES III was conducted from 1988 through 1994. The first phase started in 1988 and ended in 1991. The second phase commenced in 1992 and ended in 1994. NHANES became a continuous annual survey from 1999. For the current study data obtained during 1999 to 2006 were utilized. A representative sample of the civilian, non-institutionalized U.S. population was selected using a stratified multistage sampling design. Participants were asked to visit the mobile examination center, where they completed questionnaires and underwent physical examinations. Using standardized methods and equipment, body measurements were performed similarly to those in NHANES III.

\section{STATISTICAL ANALYSIS:}

In 2011 statistical analyses were performed with Stata version 11 using techniques appropriate for the complex NHANES survey design. All of the analyses used the NHANES-provided sampling weights so that results are representative of the US population. The data of NHANES III (1988-1994) and NHANES 19992006 cycles i.e.,( NHANES III Phase I 1988-1991; NHANES III, Phase II 1991-1994; NHANES 19992000; NHANES 2001-2002; NHANES 2003-2004 and NHANES 2005-2006) were utilized. The crude WRT means of NHANES surveys as well as their corresponding standard errors were calculated. Standard errors were estimated using the Taylor series linearization method. The US 2000 population was used to calculate age standardized WTR means. Age standardized estimates allow comparison of WRT means across time after removing differences in age. The statistical significance of changes in these means over time was evaluated by fitting linear regression models. In the instance where WRT means were not linear, polynomial quadratic model was conducted. In all fitted models, WTR (outcome) was included as a continuous variable while an ordinal variable representing the 6 time periods was included as a continuous independent variable in regression analyses. Finally, multivariate linear regression analyses were performed to determine the independent relationship of WTR with age, gender, race and time periods. The statistical significance was established a priori at 0.05 . 
Faramawi et al., Trends in waist to thigh ratio among adults in US

\section{RESULTS:}

Table 1. Characteristics of adults participated in NAHNES III (1988-1994) and continuous NHANES surveys (1999-2006).

\begin{tabular}{|c|c|c|c|c|c|c|}
\hline & $\begin{array}{c}\text { NHANES III } \\
\begin{array}{c}\text { 1988-1991 } \\
\text { N=7,431 }\end{array}\end{array}$ & $\begin{array}{c}\text { NHANES III } \\
\text { 1992-1994 } \\
\text { N=7,553 }\end{array}$ & $\begin{array}{c}\text { NHANES } \\
1999-2000 \\
N=4,081\end{array}$ & $\begin{array}{c}\text { NHANES } \\
2001-2002 \\
\text { N=4,503 }\end{array}$ & $\begin{array}{l}\text { NHANES } \\
2003-2004 \\
\text { N=4,190 }\end{array}$ & $\begin{array}{c}\text { NHANES } \\
\text { 2005-2006 } \\
\text { N=4,243 }\end{array}$ \\
\hline Age* & $\begin{array}{l}44.63 \\
(0.44)\end{array}$ & $44.88(0.67)$ & $45.87(0.44)$ & $46.01(0.61)$ & $46.09(0.52)$ & $46.38(0.76)$ \\
\hline \multicolumn{7}{|l|}{ Gender $^{\wedge}$} \\
\hline Male & $\begin{array}{l}47.70 \\
(0.65)\end{array}$ & $47.59(0.77)$ & $48.11(0.82)$ & $48.16(0.57)$ & $48.32(0.84)$ & $48.48(0.66)$ \\
\hline \multicolumn{7}{|l|}{ Race $^{\wedge}$} \\
\hline Whites & $\begin{array}{l}83.58 \\
(1.74)\end{array}$ & $82.30(1.59)$ & $73.13(2.80)$ & $76.01(2.22)$ & $76.55(3.41)$ & $76.24(2.75)$ \\
\hline Blacks & $11.26(1.34)$ & $11.86(1.29)$ & $10.89(1.65)$ & $11.01(1.82)$ & $11.53(1.97)$ & $11.71(2.02)$ \\
\hline Hispanics & $\begin{array}{l}5.16 \\
(0.64)\end{array}$ & $5.84(0.84)$ & $15.98(3.16)$ & $12.98(2.64)$ & $11.92(2.40)$ & $12.04(1.54)$ \\
\hline
\end{tabular}

*Values are mean and (standard error).

${ }^{\wedge}$ Values are number and (percent). 
Faramawi et al., Trends in waist to thigh ratio among adults in US

Table 2. Crude and age standardized waist to thigh ratio means from 1999 to 2006.

\begin{tabular}{|c|c|c|c|c|c|c|c|}
\hline & $\begin{array}{l}\text { NHANES III } \\
1988-1991 \\
\mathbf{N} \\
\bar{x}(\mathrm{SE})\end{array}$ & $\begin{array}{l}\text { NHANES III } \\
1992-1994 \\
\mathbf{N} \\
\bar{x}(\text { SE) }\end{array}$ & $\begin{array}{l}\text { NHANES } \\
1999-2000 \\
\mathbf{N} \\
\bar{x}(\mathrm{SE})\end{array}$ & 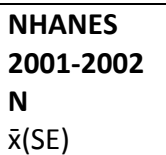 & $\begin{array}{l}\text { NHANES } \\
\text { 2003-2004 } \\
\mathbf{N} \\
\bar{x}(\mathrm{SE})\end{array}$ & $\begin{array}{l}\text { NHANES } \\
\mathbf{2 0 0 5 - 2 0 0 6} \\
\mathbf{N} \\
\bar{x}(\mathrm{SE})\end{array}$ & $\begin{array}{l}P \\
\text { value }\end{array}$ \\
\hline $\begin{array}{l}\text { Total } \\
\text { Crude } \\
\text { Age } \\
\text { standardized }\end{array}$ & $\begin{array}{l}7431 \\
1.79(0.008) \\
1.80(0.007)\end{array}$ & $\begin{array}{l}7553 \\
1.79(0.004) \\
1.80(0.005)\end{array}$ & $\begin{array}{l}4081 \\
1.80(0.008) \\
1.81(0.008)\end{array}$ & $\begin{array}{l}4503 \\
1.81(0.003) \\
1.81(0.005)\end{array}$ & $\begin{array}{l}4190 \\
1.82(0.006) \\
1.82(0.006)\end{array}$ & $\begin{array}{l}4243 \\
1.83(0.005) \\
1.83(0.009)\end{array}$ & $\begin{array}{l}<0.01 \\
<0.01\end{array}$ \\
\hline $\begin{array}{l}\text { Gender } \\
\text { Male } \\
\text { Crude } \\
\text { Age } \\
\text { standardized }\end{array}$ & $\begin{array}{l}3757 \\
1.84(0.005) \\
1.84(0.004)\end{array}$ & $\begin{array}{l}3311 \\
1.84(0.007) \\
1.85(0.005)\end{array}$ & $\begin{array}{l}1922 \\
1.85(0.008) \\
1.86(0.006)\end{array}$ & $\begin{array}{l}2153 \\
1.86(0.005) \\
1.86(0.005)\end{array}$ & $\begin{array}{l}2027 \\
1.87(0.008) \\
1.87(0.005)\end{array}$ & $\begin{array}{l}2050 \\
1.88(0.001) \\
1.88(0.006)\end{array}$ & $\begin{array}{l}<0.01 \\
<0.01\end{array}$ \\
\hline $\begin{array}{c}\text { Female } \\
\text { Crude } \\
\text { Age } \\
\text { standardized } \\
\end{array}$ & $\begin{array}{l}6374 \\
1.73(0.009) \\
1.73(0.009)\end{array}$ & $\begin{array}{l}4242 \\
1.74(0.008) \\
1.73(0.004)\end{array}$ & $\begin{array}{l}2159 \\
1.74(0.006) \\
1.74(0.010)\end{array}$ & $\begin{array}{l}2350 \\
1.75(0.006) \\
1.75(0.006)\end{array}$ & $\begin{array}{l}2163 \\
1.77(0.006) \\
1.77(0.004)\end{array}$ & $\begin{array}{l}2193 \\
1.79(0.010) \\
1.78(0.007)\end{array}$ & $\begin{array}{l}<0.01 \\
<0.01\end{array}$ \\
\hline $\begin{array}{l}\text { Race } \\
\text { White } \\
\text { Crude } \\
\text { Age } \\
\text { standardized }\end{array}$ & $\begin{array}{l}3396 \\
1.80(0.007) \\
1.79(0.007)\end{array}$ & $\begin{array}{l}3038 \\
1.80(0.006) \\
1.80(0.004)\end{array}$ & $\begin{array}{l}\mathbf{1 , 8 8 9} \\
1.81(0.009) \\
1.80(0.007)\end{array}$ & $\begin{array}{l}2442 \\
1.82(0.004) \\
1.81(0.005)\end{array}$ & $\begin{array}{l}2324 \\
1.83(0.006) \\
1.82(0.004)\end{array}$ & $\begin{array}{l}2217 \\
1.84(0.009) \\
1.83(0.006)\end{array}$ & $\begin{array}{l}<0.01 \\
<0.01\end{array}$ \\
\hline $\begin{array}{c}\text { Black } \\
\text { Crude } \\
\text { Age } \\
\text { standardized }\end{array}$ & $\begin{array}{l}1958 \\
1.69(0.006) \\
1.71(0.005)\end{array}$ & $\begin{array}{l}2344 \\
1.69(0.007) \\
1.71(0.006)\end{array}$ & $\begin{array}{l}777 \\
1.70(0.005) \\
1.73(0.005)\end{array}$ & $\begin{array}{l}889 \\
1.71(0.010) \\
1.73(0.008)\end{array}$ & $\begin{array}{l}851 \\
1.72(0.006) \\
1.74(0.005)\end{array}$ & $\begin{array}{l}987 \\
1.73(0.006) \\
1.75(0.006)\end{array}$ & $\begin{array}{l}<0.01 \\
<0.01\end{array}$ \\
\hline $\begin{array}{l}\text { Hispanic } \\
\text { Crude } \\
\text { Age } \\
\text { standardized }\end{array}$ & $\begin{array}{l}2077 \\
1.83(0.010) \\
1.89(0.006)\end{array}$ & $\begin{array}{l}2171 \\
1.81(0.050) \\
1.87(0.004)\end{array}$ & $\begin{array}{l}1415 \\
1.79(0.010) \\
1.83(0.010)\end{array}$ & $\begin{array}{l}1172 \\
1.80(0.009) \\
1.85(0.010)\end{array}$ & $\begin{array}{l}1015 \\
1.82(0.008) \\
1.86(0.009)\end{array}$ & $\begin{array}{l}1039 \\
1.85(0.010) \\
1.89(0.010)\end{array}$ & $\begin{array}{l}<0.01 \\
<0.01\end{array}$ \\
\hline
\end{tabular}

$\overline{\mathrm{x}}=$ Mean $\quad(\mathrm{SE})=($ Standard Error)

Table 3. The relationship of waist to thigh ratio to age, gender, race and time periods.

\begin{tabular}{|l|l|l|l|}
\hline & \multicolumn{3}{|c|}{$\mathrm{N}=32,001$} \\
\hline Age ( years ) & B & SE & P \\
\hline $\begin{array}{l}\text { Gender } \\
\text { Males ( }=16781) \text { versus females ( }=15220)\end{array}$ & 0.007 & 0.001 & $<0.01$ \\
\hline $\begin{array}{l}\text { Race } \\
\text { Whites ( }=15306) \text { versus blacks ( }=7806)\end{array}$ & 0.110 & 0.003 & $<0.01$ \\
Hispanics (n=8889) versus blacks (n=7806) & 0.060 & 0.004 & $<0.01$ \\
\hline Year & 0.120 & 0.005 & $<0.01$ \\
\hline
\end{tabular}


Figure 1 Trends of waist to thigh ratio by gender

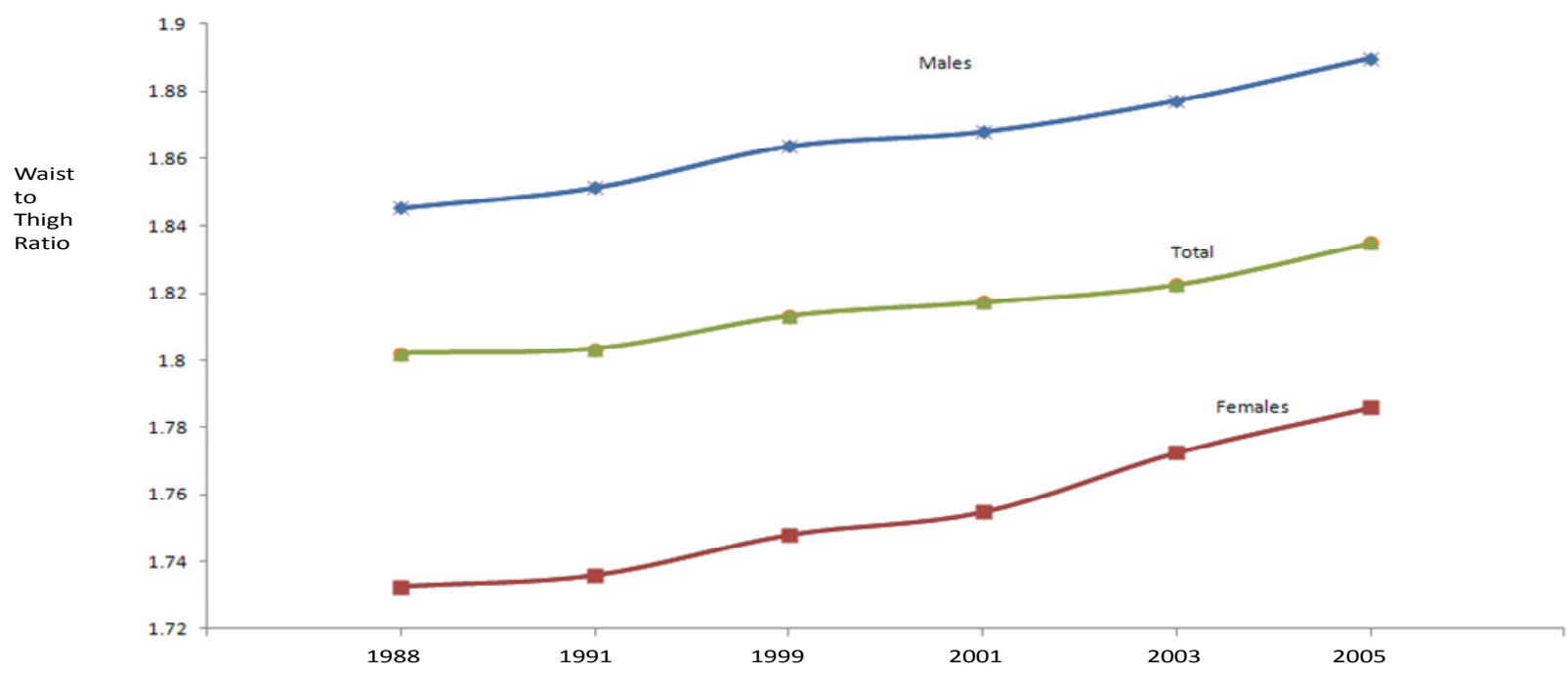

Figure 2 Trends of waist to thigh ratio by race

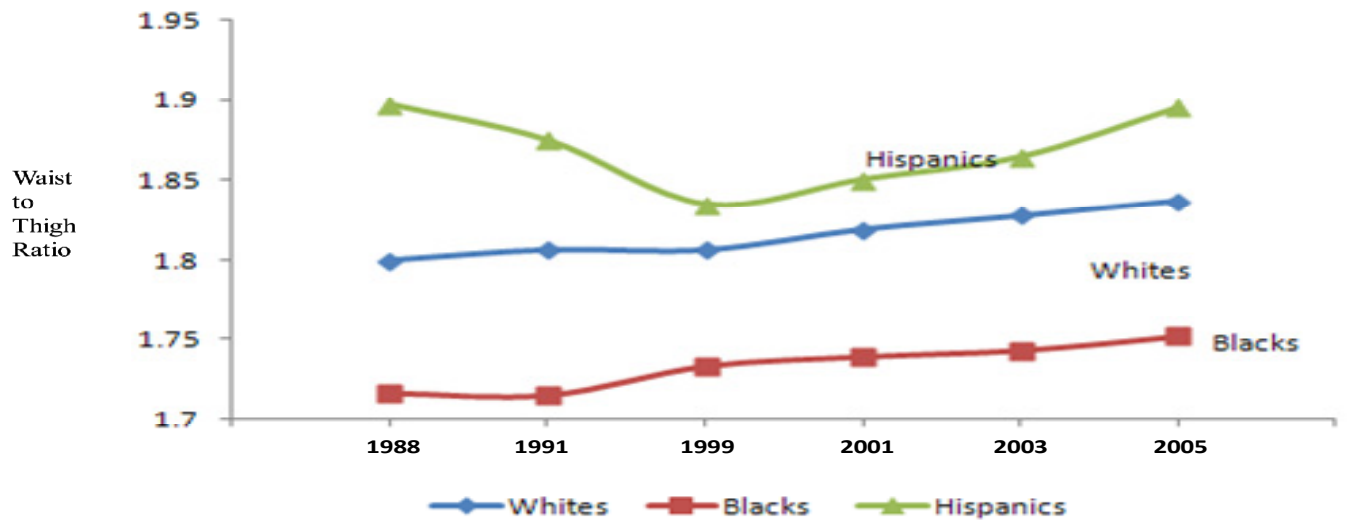

Table 1 demonstrates the characteristics of NHANES III (1988-1994) and continuous NHANES surveys (1999-2006). Table 2 and graph 1 show that the total crude and standardized WRT means of NAHNES surveys increased across years. Males' and females' WTR means increased over time (Table 2 and Fig. 1). Table 2 and fig. 2 show that Whites' and Blacks' WRT means increased across the studied years. The mean WRT of Hispanics decreased between 1988 and 1994. Yet, it started to increase beginning from 1999. Age, gender, race and time periods were significant predictors for WRT (Table 3). As age increased the mean WTR increased. Males had greater mean WRT than females (Table 2 and Fig. 1). Finally, in comparison to Whites and Blacks, Hispanics had the highest WRT (Table 2 and Fig. 2). All previous results were statistically significant (P values $<0.01)$. 


\section{DISCUSSION AND CONCLUSIONS}

This study documents an increase in WTR among U.S. adults over time. As the epidemic of obesity increases, (Wang et al.,2008, Young and Nestle,2002) it is not surprising that there was a corresponding increase in the nation's WTR. The increase was observed among males, females and different racial groups. This increase remained significant after age standardization. Although there was an initial decrease in the WTR among Hispanics before 1999, the WTR started to increase beginning from 1999. Multivariate linear regression revealed that age, gender, race and years were significant predictors for WRT. WTR as a measure of body fat distribution carries important information for identifying adults at an increased risk for mortality, cardiovascular disease (Kahn et al.,1996, Lu et al.) and diabetes mellitus (Chuang et al.,2006, Kaur et al.,2008, Weyer et al.,1999). Therefore, WTR can be utilized as an inexpensive screening tool for approximating unhealthy body shapes and hence to provide clues for future preventive medicine. This study has characteristics which make it unique. The current study is among the first to provide a look at the obesity epidemic from the perspective of WTR. Second, NHANES surveys are large, nationally representative surveys with standardized data collection procedures

(Faramawi et al.,2010, Faramawi et al.,2011, Faramawi et al.,2008). Third, waist and thigh measures were obtained by trained study staff using standardized protocols, which avoid the known biases of self-reported body circumferences.

In essence, the increase in the WTR, a simple practical measure of central obesity, among the U.S adults necessitates the concerted efforts of public health professionals and clinicians to make necessary recommendations in order to decrease the nation's WTR. Should health professionals be able to achieve that, this would decrease the risk of important chronic diseases particularly diabetes mellitus and cardiovascular diseases.

\section{REFERENCES}

Flegal K.M., Carroll M.D., Ogden C.L., Johnson C.L., (2002). Prevalence and Trends in Obesity Among US Adults, 1999-2000. JAMA.288(14),1723-1727.

Mokdad A.H., Ford E.S., Bowman B.A., Dietz W.H., Vinicor F., Bales V.S., et al., (2003). Prevalence of Obesity, Diabetes, and Obesity-Related Health Risk Factors, 2001. JAMA.289(1),76-79.

Li C., Ford E.S., Zhao G., Kahn H.S., Mokdad A.H., (2010). Waist-to-thigh ratio and diabetes among US adults: The Third National Health and Nutrition Examination Survey. Diabetes Res Clin Pract.89(1),79-87.

Reis J.P., Macera C.A., Araneta M.R., Lindsay S.P., Marshall S.J., Wingard D.L., (2009). Comparison of Overall Obesity and Body Fat Distribution in Predicting Risk of Mortality. Obesity.17(6),12321239.

Chuang Y.C., Hsu K.H., Hwang C.J., Hu P.M., Lin T.M., Chiou W.K., (2006). Waist-to-thigh ratio can also be a better indicator associated with type 2 diabetes than traditional anthropometrical measurements in Taiwan population. Ann Epidemiol.16(5),321-331.

Kaur P., Radhakrishnan E., Sankarasubbaiyan S., Rao S.R., Kondalsamy-Chennakesavan S., Rao T.V., et al., (2008). A comparison of anthropometric indices for predicting hypertension and type 2 diabetes in a male industrial population of Chennai, South India. Ethn Dis.18(1),31-36.

Weyer C., Bogardus C., Pratley R.E., (1999). Metabolic characteristics of individuals with impaired fasting glucose and/or impaired glucose tolerance. Diabetes.48(11),2197-2203.

Kahn H.S., Austin H., Williamson D.F., Arensberg D., (1996). Simple anthropometric indices associated with ischemic heart disease. J Clin Epidemiol.49(9),1017-1024.

Wang Y., Beydoun M.A., Liang L., Caballero B., Kumanyika S.K., (2008). Will all Americans become overweight or obese? estimating the progression and cost of the US obesity epidemic. Obesity (Silver Spring).16(10),2323-2330. 
Faramawi et al., Trends in waist to thigh ratio among adults in US

Young L.R., Nestle M., (2002). The contribution of expanding portion sizes to the US obesity epidemic. Am J Public Health.92(2),246-249.

Lu B., Zhou J., Waring M.E., Parker D.R., Eaton C.B., (2010). Abdominal obesity and peripheral vascular disease in men and women: a comparison of waist-to-thigh ratio and waist circumference as measures of abdominal obesity. Atherosclerosis.208(1),253-257.

Faramawi, Mohammed F., Caffrey, James L., (2010). Linking higher physical activity to lower serum cystatin C among US adults. J Public Health.18,515-521.

Faramawi M.F., Caffrey J.L., Amanzadeh J., Sharpa L.D., Qualls-Hampton R., (2011). Cystatin C estimated renal dysfunction predicts $T$ wave axis deviation in US adults: results from NHANES III. Eur J Epidemiol.26(2),101-107.

Faramawi M.F., Wildman R.P., Gustat J., Rice J., Abdul Kareem M.Y., (2008). The association of the metabolic syndrome with QTc interval in NHANES III. Eur J Epidemiol.23(7),459-465. 